\title{
Llegada del Prof. Dr. med. Alexander Lipschūtz
}

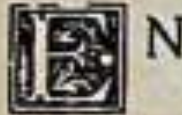

N la última semana del mes de Agosto llega a nuestro pais el profesor doctor Lipschülz, que, como se sabe. ha sido contratado por la Universidad de Concepción a fin de que sirva la cáledra de Fisiologia y dirija el Laboralorio correspondiente en nuestras Escuelas de Medicina y Dentistica.

Con ocasión de este hecho, y como un homenaje al sabio investigador que pronto ha de incorporarse a las actividades de nuestra Universidad. ATENEA se complace en insertar algunos datos relativos a la vida docente del reputado profesor y a la bibliografia con que ha enriquecido las investigaciones fisiológicas modernas, datos que se ha servido proporcionarnos el profesor de nuestra Universidad, doctor Oltmar Wilhelm.

Nació el doctor Lipschülz en Riga, el año 1883.-Después de estudiar en las Universidades de Berlin, Göttingen y Zürich. recibió su doclorado en medicina en 1907, en Göllingen. Perfeccionó en seguida sus estudios médicos en varios Institutos cientificos principalmente en Alemania y Suiza, desempeñando en varios de ellos, como en el Instituto para Epilépticos, en Zürich, y otros, diversos cargos de importancia. Ya en 1913 era uno de los más destacados colaboradores cientificos en el Instítuto Fisiológico del gran sabio fisiólogo Verwern, en Göttingen, y después en Bonn. En 1916 trabajó en los laboratorios del célebre Prof. E. Steinach, en Viena (Instituto de Investigación Biológica de la Academia de Ciencias, Viena), De 1915 a 1919. libre docente de la cátedra de Fisiologia en la Universidad de Berna; desde 1919, profesor de Fisiologia y Director del Institulo Fisiológico de la Universidad de Dorpat. 
puesto que ha desempeñado hasta que fueron contratados el presente año sus servicios para las clases de Fisiologia de la Universidad de Concepción. Su enorme y fecunda labor cientifica, en la cual merecen especial mención sus trabajos sobre endocrinologia sexual, publicados regularmente en el .Anzeiger der Akademie der Wissenschaften, Wien: .Comples Rendus de la Societé de Biologies. Paris; Proceedings of the Royal Society., London; .Pflügers Archiv fuer die gesamte Physiologie. Berlin, etc., efc.. como asimismo sus interesantes obras -Allgemeine Physiologie des Todes.. Braunschweig, 1915; .Zur allgemeinen Physiologie des Hungers,. Braunschweig. 1915: ¿Physiologie und Entwicklungsgeschichte., Jena, 1916: .Ueber den Einfluss der Ernährung auf die Körpergrösse., Berna. 1917: .Probleme der Volksernährung., Berna, 1917: .Die Pubertätsdrüse und ihre Wirkungen.. Berna, 1919 (que es considerada como una de las obras de mayor importancia del autor y que traducida al inglés y al español. Lué editada respectiva: mente por Heffer \& Sons, Cambridge, y por Calpe, Madrid). fuera de los innumerables trabajos de investigación publicados en diversos archivos cientificos, revelan la personalidad del sabio que llega a la Universidad de Concepción. 